\title{
The Anatomy of a Transformation: An Analysis of the Psychological Structure of Four Near-Death Experiences
}

\author{
Patti R. White, Ph.D. \\ La Mesa, CA
}

ABSTRACT: In this paper, I discuss the general psychological structure of four near-death experiences and the evolutionary nature of the mental processes that occur. I suggest that the transformational aspect of each neardeath experience comes at the culmination of the mental processes through archetypal imagery drawn from the context of the experiencer's life.

Researchers have studied the phenomenon of the near-death experience (NDE) from many angles. They have attempted to find variables that might correlate with NDEs, such as age, sex, religion, socioeconomic status, and severity of physical trauma during the NDE. Ultimately, there seems to be no significant relationship between demographics, religious affiliation, or religiosity and the likelihood of a near-death experience (Mickel, 1985; Osis and Haraldsson, 1977; Ring, 1984). Studies to date have found that nearly all neardeath experiences deeply and positively transform the people who have them, and that there is a strong belief in life after death as a result of this transformation (Groth-Marnat and Schumaker, 1989; Moody and Perry, 1988; Rhodes, 1990).

This transformational aspect of the NDE appears to be the end result of a psychological process in which the NDEr encounters "some

Patti R. White, Ph.D., is a psychotherapist in private practice, a Certified Trauma Specialist, and Adjunct Faculty member with The Union Institute College of Undergraduate Studies in San Diego, CA. This paper was based on her doctoral dissertation at The Union Institute, Cincinnati, $O H$. Reprint requests should be addressed to Dr. White at 10070 Lemon Avenue, La Mesa, CA 91941. 
of the deepest structures of the psyche" (Bache, 1994, p. 42). In the process, the ego is confronted by its own illusion, which leads to a recalculation, as it were, of reality. Kenneth Ring wrote that "we take our ego with us into the first stages of the NDE where we retain our sense of separateness. ... [I]t is the lens through which we have become accustomed to see the world" $(1994,60)$. The NDEr's egobased reality is overwhelmed by the omniscient and universal reality of the light, and a point of reference is created from which life and death have transcendental meaning thereafter.

David Feinstein wrote:

A principal consequence of NDEs ... is that life takes on a different meaning when it is understood within the context of a larger story. One seeks to discover not only the local code for right action, but the code that is part of this bigger plan. The attitudinal changes that researchers have consistently identified following NDEs ... provide a phenomenological list of the emotional, cognitive, and spiritual changes associated with assuming an experience-based belief in an afterlife. (Feinstein, 1990, p. 263)

This paper presents four near-death experiences as psychological profiles in which their structure, essence, and personal impact are explored, compartmentalizes each NDE to examine the evolutionary nature of the mental processes involved, and takes a closer look at the transformational aspect represented through the archetypal imagery within each NDE. The archetypal imagery reflects the context of each experiencer's life in such a way that the psyche understands that which must be transformed because the ego has been transcended through this altered state of consciousness. In other words, to paraphrase Feinstein, our lives are put into perspective once we see the big picture.

John Pennachio wrote that "Ego transcendence frequently accompanies catharsis and regeneration. Catharsis and regeneration are powerful instruments for transformation and are often referred to as a death/rebirth experience" $(1988$, p. 164). The "death/rebirth" experience is foundational to the mental processes of the four NDEs presented here and further supports the transformational aspect as a "restorative function inherent in the psyche that facilitates catharsis and self-healing" (Pennachio, 1988, p. 167).

P.M.H. Atwater described this transformational aspect of the NDE as a "growth event that allows for a course correction" in a person's life to change whatever is "weak or missing in character development" (1992, p. 157). I apply her model of the four types of near-death 
experiences to each of the four NDEs presented here, to illustrate how the archetypal imagery promotes personal transformation through a course correction in each experiencer's life.

\section{The General Psychological Structure of the Near-Death Experience}

Based on Amedeo Giorgi's (1975) methodological outline, the complexity of the near-death phenomenon can be examined under four headings to depict its psychological process: the Before stage delineates what was going on for the NDEr cognitively and emotionally immediately before the near-death experience; the Emergence stage describes what was happening cognitively and emotionally as the near-death experience commenced; the Configuration of the NDE stage portrays the NDEr's mental processes and feelings within the structure of the near-death experience; and the After stage details the lasting effect, the transformational aspect, of the near-death experience on the person's life. These phases reflect immanent meaning and not external realities. They also do not necessarily adhere to chronological time progression, as a person may continue to live or return to earlier psychological stages. Each phase is an integral part of the whole phenomenon besides being a complete moment unto itself.

A brief synopsis of each of the four NDEs precedes the four phases of the psychological process, which includes direct quotes from interviews with the experiencers. All names have been changed for reasons of confidentiality.

\section{Case \#1: Emily's NDE}

Emily is a 44-year-old divorced Caucasian woman with four children, who is a health professional at a major university. She had her NDE at age 29, 12 weeks after giving birth to her fourth child. Due to birth complications, she returned to the hospital for a vaginal hysterectomy and expected to be in the hospital only 48 hours. After her surgery, she began to experience chest pain and within several hours she became more uncomfortable and anxious. She began going into shock, 12 hours after her operation, from undetected bleeding in her abdomen. She was returned to the operating room in an attempt to drain the blood. 
The near-death experience began when she was on the operating table. She felt disoriented and a rocking sensation as she entered a tunnel. There was no sound. She remembers leaving her end of the tunnel and walking toward a light at the other end. About halfway through the tunnel, she heard her husband's voice saying, "This is the only wife I have!" She felt herself slipping backwards into her body.

\section{The General Psychological Structure of Emily's NDE}

Before. Before her NDE, Emily was already going through a very stressful situation that was not at all an everyday experience: namely, the birth of her fourth child before the age of 30 ; severe complications that necessitated surgery, which would leave her unable to bear any more children; and unpredictable complications to that surgery, which left her near death.

Emily was not prepared to die when she went in for the hysterectomy. Indeed, she had expected to be hospitalized only for 48 hours: "I was still nursing my 12-week-old baby girl." Being a medical technician herself and having a doctor for a husband, Emily felt confident that she understood the forthcoming medical procedures and risks. Her intention was to have a vaginal hysterectomy, recuperate for a few days, and return home to her family.

The Emergence. Unannounced and unexpected, another theme began to emerge, which shattered the expectation of a routine medical procedure and Emily's plans to resume ordinary life. Emily remembers:

Unknown to the medical staff, there was a slow bleeding process in my peritoneum. Several hours after my surgery, I began to experience a great deal of chest pain. I was uncomfortable and anxious.

As Emily began to become aware of her increasing pain, she remained confident that the medical staff would rectify the problem. Emily accepted the pain medication and noted that she was being given "three or four times the normal amount." Emily was conscious through the entire second operation and had "memories of faces and hands and name tags of nurses and doctors."

The Configuration of the Near-Death Experience. The structure of Emily's near-death experience had four constituents: (1) a feeling of disorientation; (2) the tunnel and feelings of comfort; (3) the light; and (4) return to the physical body. 
First, Emily began to feel disoriented and had "a rocking feeling." She heard no sound and there was an aura of softness. She was no longer in the familiar operating room but rather in a "different realm." Second, Emily had the distinct feeling of being separate from her physical body. She felt as if she had entered a tunnel-type room and had a pronounced sense of fearlessness, gentleness, and comfort. She recounted:

I remember it felt cold at first and then I became comfortable in terms of temperature. At first it was very quiet and then I think there was a sound like an ocean wave. I didn't feel like I was walking through the tunnel; it was more like floating.

Emily intellectualized what she was experiencing in an attempt to understand it: "I had it real memorized because I was in there for a long time." She described the following:

The tunnel was bluish-silver and it felt like it got narrower as I traveled through it. It enveloped me rather closely but comfortable enough so that I could reach out to the sides. There was a light at the end of the tunnel. I was attracted to it and it welcomed me.

Third, when Emily described the light experience, her intellectualizing was temporarily suspended and she became emotional:

I was attracted to the light, not in a harsh way but a gentle way.

The light was so loving. The closer I got to it, the warmer it became.

The light was misty and an incredibly intense whiteness. I never saw that color before. Not blinding, but then, I did not get that close to it.

The prior disorientation had clearly stopped and had been replaced by fascination and a continued sense of peace.

Fourth, as Emily was proceeding toward the light with an increasing willingness to release and let go, another unexpected theme emerged. Halfway through the tunnel, she suddenly heard her husband's voice saying, "This is the only wife I have!" Immediately she felt herself moving backwards and "slipping back with a sense of speed" into her body. Back in the physical body, the pain from the needles in her arm and awareness of the operating room returned. There was no transition period and no sense of being able to control the return.

In an instant, there was a multitude of feelings: emptiness, from leaving the splendor of the light; pain, from the needles in her arm; confusion, from the nurses and doctors responding to her husband's angry outburst ("If I hadn't come in here you would have killed her!"); 
and confusion over whether she had a choice to return. Emily lost consciousness upon reentry into her body.

After. Emily spent a good deal of time reflecting upon her NDE during the next year as she recovered, and it was difficult for her to find someone to talk to for fear of being ridiculed or not believed. Emily chose to tell her twin sister, the only person who knew her for a long time. To this day, 15 years later, she is still quite selective as to whom she tells: "I have to feel safe."

The predominant theme in this After stage was one of ambivalence. Why didn't she die? she asked herself. If she had been given a choice, she "would have continued into the light," yet she "needed and wanted to take care" of her children. If this was not her time to die, what was the meaning and purpose of her near-death experience? she wondered.

With the benefit of 15 years worth of reflection, Emily feels that her NDE was a profoundly religious experience that has changed many aspects of her way of thinking. Having been raised a staunch Catholic with a rigid belief in heaven, it was "comforting to give myself permission to look into the next life" from a different perspective, which is what she assumed her NDE was all about. As a result of her NDE, she is completely convinced there is life after death and has no fear of dying. Heaven has become for her a less physical and more spiritual place. It has become more of a state of mind where all questions are answered. It has helped her take one day at a time.

Based on her NDE, Emily allowed herself to let go of the parts of the Catholic Church and teachings that she considered too rigid and appreciate the parts that she felt applied to her life. She changed her expectations regarding her children's religious training and became more open to their personal exploration. Emily began to see death as a passage to a higher realm of understanding. She believes the mysteriousness of the near-death experience has to do with what is on the other side of death. She also believes she would find the heart, mind, and spirit of God at the end of her life's journey.

\section{Case \#2: Raquel's NDE}

Raquel is a 55-year-old divorced Hispanic female who had a neardeath experience in November, 1992. It began with a yeast infection that worsened and eventually turned into blood poisoning. She went to the hospital, where doctors worked feverishly to save her life. 
Alone in a darkened hospital room two days later, she saw a black swirling hole and felt herself walking towards it. She became very frightened, wondering what it could be. She realized she must be dying, but would not accept this readily because she had so much more to do in this life. She tried crawling out of the hole, fighting every inch of the way. She felt herself flying up and looking down on her body in the bed. She watched as her body moaned with pain. Once again she was back in the whirlpool-like tunnel.

She saw her parents and her grandmother, who had died many years earlier, at the entrance of the black hole. The familiarity brought a sense of relief to her. Her grandmother kept saying, "Come on, mija." Raquel told her grandmother, no, she was too young to go. Her father said, "It's time for you to go. You have done enough. I want you to come." Once again, Raquel resisted and felt herself back in her body. She went back and forth from her body in the bed to the tunnel at least three times. She began praying, telling God she could not die because her children needed her and she had no husband to support them. She felt herself crawl out of the tunnel one final time. As she was crawling out, she saw a bright light to her right. The light must be heaven, she thought, but she was still determined to get back to this life. As her determination grew, the light faded.

\section{The General Psychological Structure of Raquel's NDE}

Before. At the age of 55, Raquel was hardly slowing down. A selfproclaimed workaholic, she was quite active in the community as a public health worker and avid Latino rights supporter. Her diabetes had been under control for some time and a yeast infection posed no great health threat under normal circumstances. Unfortunately, this was not to be the case, as the yeast infection developed into blood poisoning, a possibly fatal condition.

The Emergence. Raquel was taken off guard by the swift onset and spread of the infection. Everything was alarming her, even the ambulance ride to the hospital, because she was quickly losing control over her ability to make decisions for herself. Her memories of the hospital included many doctors and nurses working feverishly over her trying to get a pulse, to stabilize her blood sugar, and to control the infection. She remembered awakening in her hospital room two days later. 
The Configuration of the Near-Death Experience. The structure of Raquel's near-death experience had six constituents: (1) the black hole; (2) the out-of-body experience; (3) meeting her relatives; (4) the struggle to return; (5) the light; and (6) the return to the physical body.

First, as she began to become aware of her hospital room, Raquel noticed the room was very brightly lit. Her attention was drawn towards a swirling black hole in the middle of the room. "Wow," she thought, "this is really dark!" As it continued to swirl like a whirlpool, she became frightened: "Oh, my God, what is this? I've heard of whirlpools in the water and tornadoes, but what is this?"

The next sensation she felt was being drawn into the black whirlpool and she fought to stop slipping into it. Immediately, she panicked: "I must be dying. I've never been this sick before. But I can't die-I have too much to do."

Second, she felt herself suddenly flying up and looking down on herself in the bed. She saw herself lying there struggling to live. "Nobody's here to help me," she thought. With that, she was pulled back into the tunnel.

Raquel seemed to have no choice whether she stayed in her body or was thrust back into the tunnel. This helplessness exacerbated her fear and resistance. No matter how sick her body was, she was adamant about returning to it. The alternative-the black swirling hole-did not seem a viable option.

Third, as she surveyed the black hole trying to find a way out, she looked toward the tunnel entrance. Standing on the outside of the tunnel were her parents and grandmother, all of whom had died many years earlier. She was initially happy and relieved to see them.

Her grandmother kept saying in Spanish, "Come with us." "No, no, no!" Raquel screamed, "I'm too young! Not yet!" Her father said, "It's time for you to come. You've done enough. I want you to come." Again, Raquel cried no.

Fourth, she returned to her body as she began crying and resisting her relatives' request to stay. Could she will herself out of the hole? she wondered. She remembered slipping back into the hole and struggling out three more times, each time ignoring the pleas from her relatives to stay. Finally, she prayed to God to help her return to her six children. She crawled out of the tunnel and never looked back.

Fifth, as she crawled out she saw a very bright light to her right. The room was flooded with its brightness. She felt a peacefulness 
she had never known and wondered if this was the final step before heaven. The contrast was striking between the terror she felt in the black hole and the serenity she felt in the presence of the light.

Sixth, regardless of how beautiful the light was, Raquel was still determined to return to this life. The light began to grow dimmer as she expressed the desire to go back to her body.

After. The echoing theme throughout Raquel's NDE was one of tremendous resistance to giving up her life. The black hole was a very frightening experience and, although she never got to the end of the tunnel, she thought it might have been hell because she felt the darkness at the end held no hope. There was a time in Raquel's life when she was an atheist and operated with very little conscience. The darkness reminded her of the time in her life when she had very little hope. But that time had passed and Raquel once again became involved in spiritual exploration, and she had a strong belief in God and in life after death at the time of her near-death experience. Her spiritual beliefs did not, however, dull the terror she felt in the dark hole.

Raquel believed that her own spiritual power and prayer rescued her from the black hole. Her will to continue her life's work and to be with her family was stronger than the welcoming sight of her parents and grandmother. Even the light's allure did not persuade Raquel to stay. She was not ready to die and was not going to submit without a fight. Retaining her control and exercising her choice to live or die proved to be the most powerful forces to return her to this life.

\section{Case \#3: John's NDE}

John is a 34-year-old divorced Caucasian man. On February 22, 1992 , he and his partner were working on a construction project using nail guns. It is still unclear exactly how the two men ended up facing each other, but John's partner fell against him and John ended up shooting himself with his own nail gun. A one-and-three-quarterinch finishing nail went directly into his heart through the sternum. With every heart beat, the nail was tearing a bigger hole in his heart. The pain became intense and everything got fuzzy. All of a sudden, John saw himself lying on his back with his arms folded across his chest, looking straight up. There were two waves of light coming over him. A huge right hand moved over the top of him, hovering about 
three feet above him. John believed this was God's hand. A loving voice said, "You're all right. I like you." He could then hear people yelling all around and then he heard someone yell, "He's back!"

\section{The General Psychological Structure of John's NDE}

Before. John's Before stage consisted of a typical work day with his partner at a construction site. They were working at a steady pace, shooting finishing nails into a beam. The two men were accomplished carpenters and had been on scaffolding many times. Both workers remember taking the necessary precautions and had not compromised their safety.

The Emergence. It is still open to conjecture how the two men happened to fall into each other on the scaffolding. Apparently, John's partner lost his balance and fell toward John. In the commotion, John's nail gun turned inward. John shot himself in the heart with a one-and-three-quarter-inch finishing nail. He looked at his partner and said, "I'm shot in the heart. I don't believe I am going to die!" The two men stood looking at each other for a split second. Quickly, they left the scaffolding and hurried toward their truck. John remembers panicking as his neck and chest started to throb with pain. His partner told him later that he went into convulsions, slamming his head and arm into the dashboard of the truck. He even kicked the stickshift and threw the truck into reverse.

During this stage, John was incredulous about what just happened and clearly frightened he would die. As the pain intensified, he was fighting to adapt to the unfamiliar and strange turn of events. There was not a hint of denial about the situation as John immediately understood getting shot in the heart is most likely fatal. "I was not afraid of death but I was afraid of how I was dying. I knew something was happening . . . but what?"

The Configuration of the Near-Death Experience. The structure of John's near-death experience had four constituents: (1) entering a different realm; (2) waves of light; (3) the hand of God; and (4) return to the physical body.

First, John suddenly saw himself lying on his back with his arms folded across his chest and his ankles crossed. He still felt the physical pain of his injuries but knew he was not in the truck anymore. He remembered thinking that he might be having a near-death experience because he had heard about them. But where was the tun- 
nel and the light? The remarkable feature of this stage was that John was not afraid and indeed was curious about his predicament. Having some prior knowledge that he was in the preliminary phase of a near-death experience perhaps reduced his anxiety. He was now in a state of expectancy.

Second, as he was lying there, a wave of brilliant light came over him. "What do you want me to do?" he asked the light. With that, a second even more brilliant light came over his head and the pain left. John described it as "turning over"; the absence of pain marked a higher level, a level of bliss. An ineffable feeling of awe and peace overwhelmed him and he wanted to stay there in that place.

Third, as the second wave of light shone, a large right hand slowly positioned itself over the top of John covering the length of his body, hovering about three feet above him. The hand was the brightest white imaginable and he could see the outline of the fingers as if they were finely sketched in pencil. The hand represented God and John began asking Him what he should do. A voice said, "You are all right. I like you." The hand withdrew and the first wave of light returned, and with it all the physical pain.

Finally, John became conscious as they were preparing to load him onto a helicopter that would take him to the hospital. As he lay on the asphalt he felt the pain and thought about the realm he just experienced. He closed his eyes and prayed to go back to the hand and the light. When he opened his eyes again, he realized he had not returned and he felt angry. Who would not trade total bliss for excruciating pain? John did what he could to stay alive from that point on, but began to reevaluate his life right there on the asphalt.

After. John's partner commented on how calm he was once he regained consciousness on the asphalt. John told him he had been in a "much better place." The first person he told was a therapist whom his employer generously offered. He remembers asking the therapist, "Who would believe me about the near-death experience?" She answered, "Who wouldn't?" Even though John knows he did not have an hallucination or a dream, and in spite of the fact his near-death experience seemed all too real, he has continued to seek reassurance.

John believes his NDE had changed his life "big time." Never again would work be his first priority. From now on, he would appreciate life and help others and not dwell on the small things. For a long while after his accident, however, he had difficulty concentrating and 
focusing on his daily tasks. The magnitude of his experience has taken some time to integrate into his life.

\section{Case \#4: Jill's NDE}

Jill is a 36-year-old married Caucasian woman who had an NDE at the age of 31 . While training for a marathon, she experienced fever and stomach cramps so severe that she went to the hospital. When she was examined, the doctors found a large mass within the abdominal cavity. She had her near-death experience after surgery, while in the recovery room. Jill had become a born-again Christian one year prior to her NDE and at the moment she knew she was dying, she asked Jesus Christ's forgiveness and mentally said goodbye to her loved ones. Suddenly there was a very bright light permeating her room and she heard someone speaking to her. "Who are you?" she asked. "The One Who loves you the most," a male voice replied. The voice continued to speak to her revealing the most amazing things about her life and the universe. An invisible hand lifted her out of bed with tubes and intravenous lines still attached to her body. She cried out for Jesus and was told that she would live, but that her life as she knew it was over. She was spared death to begin a new life of love and service to the Lord. Her life was forever changed from that moment.

\section{The General Psychological Structure of Jill's NDE}

Before. Before Jill's near-death experience, her mind and body were preoccupied with training for a marathon. She admits to:

an excessively brutal training with borderline anorexia, lack of proper nutrition, plus a host of emotional problems, all adding up to intense stress that, over a sustained period of time, had taken its toll upon me.

Jill had accepted Jesus Christ as her Lord and Savior one year previous to her emergency surgery. She remembers the day she recited the prayer of the covenant to the Lord and did not "feel any different." How do people feel when they are "saved"? she wondered at the time. Secretly, Jill felt like a fraud, as though she were pretending to be a Christian. She knew she was not suddenly pure or 
holy just because she had been baptized and labeled "born again." She continued her life with all the same old patterns and habits because nothing had really changed in her heart and mind.

The Emergence. The theme for Jill's emergence stage was one of shock, disbelief, and guilt that she had abused her body so badly. She remembers thinking, "I am responsible for my own demise. I had not treated my body as God's temple." Now, she found herself in the hospital with forms being thrust into her hand to sign, granting permission for the surgeons to "remove any organ they wished to." This was a far cry from the early moments when she thought she had the flu. The medical staff recommended a blood transfusion, as she had apparently lost a lot of her blood supply in surgery. Jill refused the transfusion for fear of inadvertently being infected by the AIDS virus: "I believed I was getting ready to die." Even in this state of preparedness, Jill was hardly expecting what was going to happen next.

The Configuration of the Near-Death Experience. The structure of Jill's near-death experience had four constituents: (1) the abrupt awakening; (2) a presence and a voice; (3) the life review; and (4) Jesus' message.

First, having made her peace with God by asking His forgiveness and mentally saying goodbye to her loved ones, Jill remembered:

I completely let go and disappeared into the darkness of death. Extremely abruptly, I was jolted awake. Had I been asleep? Was I coming out of a coma? I couldn't remember where I was or why. I was disoriented partly because of the anesthesia and partly because I was trying to make sense out of what was happening to me.

Jill was curious about two things: first, there had always been a steady stream of nurses and noisy carts coming in and out of her room, yet now no one could be found; and, second, in her previously darkened room, someone had turned on all the lights and they were quite brilliant. But why? The overall theme of the Emergence stage appeared to be one of bewilderment, with attempts to fit her reality into a set of circumstances that defied logic. In an attempt to cling to her reality, Jill looked down at her hospital gown and the tubes hooked to her body and found she did not recognize this physical body. Am I dying, she wondered, or am I dead?

Second, in this confusion, Jill heard someone speaking to her. "Who are you?" she asked. A male voice replied, "The One Who loves you most." It was not a voice she heard with her ears; rather it was a 
message she simply understood. Then, it was as if an invisible hand "helped lift me right out of that bed. . . . I found myself kneeling on the floor next to the bed. 'Someone' was telling me everything was going to be fine." Jill wondered again about the nurses: where were they? Jill struggled to make sense out of a situation that was beyond her comprehension.

Third, "someone" continued to speak to Jill in a clear and coherent way: "The Voice began telling me marvelous, amazing, and astonishing things about my life mainly, in a perspective I never looked at before and in a nonjudgmental way."

Jill remembers hearing about one's life flashing before one's eyes when one is about to die, and, if this were so, she figured, her life review was going to be a "horrendously miserable" picture. She was not looking forward to seeing all the mistakes she had made throughout her relatively young life. Her apprehension, however, was unfounded.

Her life review commenced with a commentary by the voice and presented an evaluation of sorts. It began when Jill was a small infant in her crib. She saw herself as a crying, kicking baby with a diaper rash. Her mother was quite upset and angry and was roughly applying lotion to the rash. As Jill watched this scene, she "knew" her mother was wishing this little baby had never been born, because she was causing too much trouble between her and her husband, Jill's father. While Jill never actually remembered this scene in her life, she realized in this review that her sense of self worth or lack thereof had been fixed at that point in her life.

The life review presented this and every other image from a nonjudgmental perspective. Jill watched her baby scene as a spectator and felt forgiveness and understanding toward her mother. After her life review ended, the voice told Jill about the universe:

It seemed like everything was being revealed to me although I cannot recall much of what those revelations were. Maybe they are still in my mind somewhere. Every single word was loaded with meaning and it went on and on for what seemed like hours.

The theme pervading Jill's life review began with cynicism surrounding the proverbial "life flashing before the eyes." She was prepared for the worst, based on the life she had led up to that point. Her cynicism was replaced by awe as she watched her life from the perspective of love and forgiveness. 
Fourth, the voice was gone and Jill found herself on her feet still hooked up to intravenous lines. She cried out to God. She was yelling and screaming and dancing and waving her arms in the air. She "babbled in some other language" and the voice suddenly returned to soothe and comfort her. As she climbed back into bed, a great sense of peace enveloped her: "It was an indescribable, overwhelming bliss." The voice said:

You will live. But you have died. There is nothing left of who you were. You will retain your memory of your past as the other person you were, and there will be times you will respond to mental stimuli provoking these memories of your former life. But that life is over. It's gone forever. You will live. But the life you have now is the life given to you by $\mathrm{Me}$; it is My life. From now on, whatever you choose to do, you will only find success and fulfillment if you live according to My word. You cannot return to your old ways ever again. If you try, you won't be able to do it. I have spared you from death and given you new life, so you will do My work on this earth. I will provide you with everything you need to carry out this work. No matter what circumstances arise, you will never be lost or confused again. For I shall remain with you always. I am real. There is something bigger and greater within you than just the fragile shell you inhabit. The flesh perishes; the Spirit lives eternally.

This segment of Jill's near-death experience was in keeping with her experience as a born-again Christian. She could recognize several characteristics, such as the speaking in tongues ("I babbled in some other language"), the charismatic-type behavior ("yelling and screaming and dancing and waving my arms in the air"), and finally, being told that she was going to die to her old way of living and be reborn to a new one ("You will live. But you have died. There is nothing left of who you were. ... [T] he life you have now is the life given to you by Me; it is My life").

After. Jill secretly mused that her family should have gone on with her funeral because she saw herself as having died and come home a different person. This was her secret that she tried to tell a few people, but they were "turned off and didn't want to hear about it." It seemed to embarrass them or make them uncomfortable. Unless they were "full blown, born-again, Bible-banging Christians, nobody knew what I was talking about."

Nothing had changed Jill's life so utterly and irrevocably. The wisdom confided to her by her Savior transformed her consciousness and allowed her to change her life direction. She never had any doubt that Jesus had spoken to her and showed her a new life. 


\section{Discussion}

The four stages of the psychological process-the before phase, the emergence phase, the configuration of the NDE, and the after phase-are by no means the definitive method for analysis of the near-death experience. They do, however, offer a method of understanding the NDEr's motivations contributing to the transformational aspect.

\section{The Before Stage}

The before stage of each of these four near-death experiences demonstrated a wide variety of everyday human conditions: Emily was a mother of four; Raquel, a workaholic; John, a construction worker; and Jill, a marathon runner. Each person's degree of religiosity or spirituality also ran the gamut from agnostic to born-again Christian: John attended church on Sundays and considered religion a routine; Emily's and Raquel's spirituality were more an integral part of their lives as they consciously incorporated religious values into everyday living; and Jill was a self-proclaimed born-again Christian silently searching for the meaning of her baptism. This study corroborated published research in finding no conclusive demographic relationship among the four case studies or the occurrence of near-death experience (Gallup and Proctor, 1982; Ring, 1984; Sabom, 1982).

\section{The Emergence Stage}

This phase dealt with each NDEr coming close to physical death and the emotional state he or she was in at the time. Of the four cases, one was an accident-John's shooting himself in the chest with a nail gun-and three were due to illness: Emily's gynecological surgery, Raquel's yeast infection, and Jill's stomach operation. A survey of NDEs conducted by Feng Zhi-ying and Liu Jian-xun found that:

alterations in state of consciousness, duration of loss of consciousness, and prior views of death influenced the content of NDEs . . . suggesting that physiological and psychological variables can influence NDE phenomenology. (1992, p. 47) 
As these four brushes with death were unintentional, the common denominator among them was the element of surprise at the unexpected onset of a potentially fatal situation. None of these four NDErs had prepared for the possibility of death, and each appeared to react within the normal range of human emotions at that moment: Emily remained confident and trusting with the medical care as she recuperated from surgery; Raquel felt vulnerable as doctors rushed to save her life; John was in excruciating pain from a nail in his heart and struggling to breathe; and Jill was shocked when she realized how sick she was and how she had neglected her body.

\section{The Configuration of the NDE and the After Stage}

Ring (1980) described the "basic thanatomimetic narrative" of the core near-death experience. This narrative addressed the developmental stages of the NDE, which included feelings of peace and calm and an ineffability of the experience; feelings of leaving the physical body; the tunnel-like experience; the appearance of the light; and entering into the light. Research on NDEs from all over the world has corroborated the universality of this thanatomimetic narrative, and the four NDEs discussed here follow the pattern as well. Ring later suggested that any deviation from this classic model may lie "especially in the deeper stages of the NDE, where more archetypal imagery comes into play" (1984, p. 47).

Carol Zaleski proposed that NDEs should be viewed as "imaginative and symbolic expressions," which, though "elusive in final meaning, are valid as one way in which the religious imagination mediates the search for ultimate truth" $(1987$, p. 191). The symbolic expressions or archetypal imagery therefore reflects the experiencer's personal, social, religious, and cultural influences, as these are what constitute the context of a person's life. The archetypal imagery facilitates ego transcendence through its pertinence to the individual's state of being. It is like a unique code that translates for the ego what must be transformed.

Four Types of Near-Death Experience

Atwater (1992) devised a model defining four types of NDEs, based on the concept that a person's life remains in context in life, at the 
moment of death, and-most likely, although understandably unsubstantiated-after death beyond the NDE. Atwater maintained that the NDE was a "growth event that allows for a 'course correction,' enabling the individual involved to focus on whatever is weak or missing in character development" $(1992$, p. 157).

Each of the four NDEs presented above falls into one of Atwater's categories of NDEs. Each NDE illustrates how the archetypal imagery is fundamental to the resulting transformation.

\section{Initial Experience ("Non-Experience")}

This type of NDE involves elements such as a loving nothingness or the living dark or a friendly voice. It is usually experienced by those who seem to need the least amount of evidence for proof of survival, or who need the least amount of shakeup in their lives. Often, this becomes a "seed" experience or an introduction to other ways of perceiving and recognizing reality. (Atwater, 1992, p. 156)

Emily's near-death experience most closely fit this category of "loving nothingness." She described herself floating through a tunnel and moving toward a peaceful light at the other end. She felt welcomed and attracted to the light and believed she would have continued on into it if it had not been for her husband's voice suddenly provoking her reentry back into her body.

The archetypal imagery in Emily's NDE reflected her already strong spiritual beliefs, appreciation for life, and duty to family. Emily had a strong belief in God and an afterlife before her neardeath experience. Raised a devout Catholic, she believed as Catholic doctrine dictated that heaven and hell were actual places and that people either went to a heavenly reward or were condemned to hell. She believed in a loving Creator and a just reward, both of which she sensed in the tunnel by the inviting light at the end. Her NDE, however, put her previous stringent religious training into perspective, giving her a greater latitude of belief with less restriction. God became more personal, and this brought her a great deal of comfort.

Her husband's voice represented the obligation she felt for her family and the decision to return to them. Emily's focus as mother and wife was clear, and her NDE was an affirmation of her life's choice. The near-death experience as a growth event allowed Emily to see her life from a different perspective, in which she first valued herself as a person who was expressing her love as a mother and wife. Later, 
when her marriage dissolved in a difficult divorce, she drew strength from the unconditional peace and serenity she had experienced in the tunnel.

\section{Unpleasant and/or Hell-Like Experience (Inner Cleansing and Self-Confrontation)}

This type of NDE involves an encounter with a bardo, limbo, or hellish purgatory, or scenes of a startling and unexpected indifference, or even "hauntings" from one's own past. It is usually experienced by those who seem to have deeply suppressed or repressed guilts, fears, and angers, and/or those who expect some kind of punishment or accountability after death. (Atwater, 1992, p. 156)

Raquel was not actively pursuing what she thought was a destructive lifestyle at the time of her near-death episode. There was no obvious reason why she had a hell-like NDE, and yet she was absolutely certain that hell was at the end of the black, swirling tunnel: "the darkness at the end held no hope." From the beginning of her near-death experience, Raquel fought to stay out of the tunnel and return to life.

The archetypal imagery of Raquel's remarkable struggle to stay out of the whirlpool was the most striking feature of her NDE, for it was reminiscent of the struggle to control her own destiny in life. Having outlived two failed marriages, she had raised six children virtually on her own. Most of the time, she was the family's sole means of support. Raquel was also politically active throughout her adult life in the Latino movement in her community to improve living conditions and ensure equal treatment for Hispanics. Her life was a portrayal of fighting against the odds, and that theme continued in her near-death experience.

Upon recovery from her illness, Raquel could hardly dismiss her intensely disturbing NDE and the lesson it tendered. She realized that her workaholic nature, her constant struggle, had contributed to her body's deterioration. She had overcontrolled every aspect of her life to the point of self-destruction. There was no control to be had in the black hole, though. Raquel felt utterly helpless and desperate.

As Raquel made her final departure from the tunnel, she saw a bright and loving light. All the turmoil and despair disappeared and was replaced by an incredible peacefulness and insight. Atwater 
wrote, "It has been my experience that whatever we need to awaken the truth of our being will manifest when we need it" (1992, p. 158). Raquel awoke from her near-death experience with a different attitude: she quit her job, allowed her body the time it needed to heal, and devoted herself to her own best interests for the first time. The anger she had repressed toward those around her and toward society at large had manifested itself physically and almost killed her. She learned there was no need to fight anything or anyone, only to love and submit to the loving peacefulness the Light offered. Raquel believed her NDE showed her a perpetual purgatory or state of limbo that awaited her, not only on the other side of death but in this lifetime, should she continue her destructive lifestyle. Upon returning to this life, Raquel gave up her job to nurse her body back to health.

\section{Pleasant and/or Heaven-Like Experience (Reassurance and Self Validation)}

This type of NDE involves heaven-like scenarios of loving family reunions with those who have died previously, reassuring religious figures or light beings, validation that life counts, affirmative and inspiring dialogue. It is usually experienced by those who most need to know how loved they are and how important life is and how every effort counts. (Atwater, 1992, pp. 156-157)

In his near-death experience, John encountered a "reassuring religious figure," God's Hand, who succinctly and omnipotently validated John's life: "You are all right. I like you." Prior to the NDE, John had been going through a divorce and facing separation from his three small children, who would be moving far away with their mother. John felt he had failed his marriage and let his children down, and the loss of his family was devastating. Against this backdrop, John had a construction accident and a near-death experience that was life-transforming.

John became emotional when he recounted his experience of suddenly finding himself lying down with his arms crossed over his chest, with waves of light moving over him, and then what he considered to be the Hand of God hovering above his body. All of his pain ceased and an incredible feeling of bliss overwhelmed him. John asked for direction and God assuaged his fears and affirmed His love: "You are all right. I like you." 
The archetypal imagery of a huge hand bringing reassurance and strength was symbolically significant for two reasons: first, John used his hands as a construction worker to support and sustain his family, the family he was now losing; and, second, it was John's own hand that shot the nail into his heart, probably to end his life.

God's Hand represented the Perfect Hand that could hold, help, and heal, everything John thought he could no longer do as a father, husband, and man. At a point in his life when he truly thought his "hands were tied," he was given another perspective and a sign through his NDE that he had the strength to "handle" the challenges of his life. The Hand was a symbol of self-renewal, self-validation, and reassurance, and, as Atwater wrote, a reminder of how loved he was and how important life was. John's NDE forced him to look at his feelings of abandonment and failure as a husband, father, and human being. John's previous low self-esteem was reframed by his NDE in terms of a spiritual awakening that God is the source of strength and consolation. John reconnected with his faith in God and in himself and renewed his commitment to the church he had been attending.

\section{Transcendent Experience (Expansive Revelations, Alternate Realities)}

This type of NDE involves exposure to otherworldly dimensions and scenes beyond the individual's frame of reference, and sometimes includes revelations of greater truths. It is usually experienced by those who are ready for a "mind stretching" challenge, and/or who are most apt to use, to whatever degree, the truths that are revealed. (Atwater, 1992, p. 157)

Jill had become a born-again Christian one year before her neardeath experience. By her own admission, at the time of her baptism, she had felt nothing special and even felt guilty she might be "pretending" to be a Christian. Her intent to be born-again was sincere; unfortunately, something was missing after her conversion that she could not identify.

In retrospect, she was primed for her near-death experience through her religious devotion and learning. She had laid the foundation for her revelatory near-death experience and embraced it with excitement. Jill listened carefully to the voice she believed to be Jesus': "The Voice began telling me marvelous, amazing, and 
astonishing things . . . in a perspective I never looked at before." Jill rejoiced in her new-found knowledge and began "dancing and waving her arms in the air and babbling in some other language." Jesus told Jill that her life as she knew it was over, in effect she had died, and she would be given a new life, Christ's life. The archetypal imagery of rebirth, dying, and taking Christ's life as her own, epitomized the concept of being born again. And Jill was born again, both spiritually and physically. Her deep desire to serve the Lord before her NDE was heightened when she experienced a personal relationship with Him through her NDE, the very element that had been missing one year before. Jill's NDE provided the bridge between her previous baptism as a born-again Christian a year before and the bliss she searched for but which eluded her as a newly committed Christian. Jill's NDE laid to rest any doubts she had about her conversion and the direction her life was to take. Her NDE empowered her to apply her Christian values to her everyday life in a practical and useful way, something she had struggled with and resisted until her body broke down.

\section{Conclusion}

These four case studies have demonstrated that the near-death experience is, in addition to a physical and spiritual process, a psychological one as well. The individual continues to experience thoughts and feelings consistent with his or her personality and life situation throughout the different phases of the NDE. The NDEr begins the journey into an altered state of consciousness where the ego is transcended, preparing the way for transformation through archetypal imagery. Archetypal imagery is the individual's unique code drawn from the context of the person's life, which allows the psyche to move from an ego-based reality to the Universal Reality. Upon returning to the physical body, the transformation is manifested through a "course correction," which enables the NDEr to focus on some aspect of his or her life that needs an adjustment at the conscious or subconscious level.

Continued study of the psychological processes of the near-death experience would have a tremendous effect on the psychology of dying, as society would no longer shun this natural transition but prepare for it. Preparation for death must come from a societal shift in values, which medical personnel, schools, families, and the public in 
general must make in order to enhance the inevitable transition. All four NDErs described above showed no fear of death after the NDE and all four looked forward to their ultimate journey into the light. Based on these data, near-death experiences reduce death anxiety and allow for course corrections in life so as to ensure a peaceful approach to death and the equanimity to accept the transition.

Finally, the near-death experience offers hope that our essence continues in some form after our bodies die. It is a comforting thought that our specialness and uniqueness are preserved as the four case studies attested to in both the pleasant and unpleasant experiences.

\section{References}

Atwater, P. M. H. (1992). Is there a hell? Surprising observations about the near-death experience. Journal of Near-Death Studies, 10, 149-160.

Bache, C. M. (1994). A perinatal interpretation of frightening near-death experiences: A dialogue with Kenneth Ring. Journal of Near-Death Studies, 13, 25-45.

Feinstein, D. (1990). Personal mythologies of death and their evolution. In G. Doore (Ed.), What survives? Contemporary explorations of life after death (pp. 255-264). Los Angeles, CA: Tarcher.

Feng Zhi-ying and Liu Jian-xun. (1992). Near-death experiences among survivors of the 1976 Tangshan earthquake. Journal of Near-Death Studies, 11, 39-48.

Gallup, G., and Proctor, W. (1982). Adventures in immortality: A look beyond the threshold of death. New York, NY: MeGraw-Hill.

Giorgi, A. (1975). An application of phenomenological method in psychology (Duquesne studies in phenomenological psychology, vol. 2). Pittsburgh, PA: Duquesne University Press.

Groth-Marnat, G., and Schumaker, J. F. (1989). The near-death experience: A review and critique. Journal of Humanistic Psychology, 19, 109-133.

Mickel, H. (1985). The near-death experience: A basic introduction. Wichita, KS: Theta Project.

Moody, R. A., and Perry, P. (1988). The light beyond. New York, NY: Bantam.

Osis, K, and Haraldsson, E. (1977). Deathbed observations by physicians and nurses: A cross-cultural survey. Journal of the American Society for Psychical Research, 71, 237-259.

Pennachio, J. (1988). Near-death experiences and self-transformation. Journal of NearDeath Studies, 6, 162-168.

Rhodes, L. (1990). The near-death experience: private or public? Journal of Near-Death Studies, 9, 71-75.

Ring, K. (1980). Life at death: A scientific investigation of the near-death experience. New York, NY: Coward, McCann and Geohegan.

Ring, K. (1984). Heading toward omega: In search of the meaning of the near-death experience. New York, NY: Morrow.

Ring, K (1994). Frightening near-death experiences revisited: A commentary on responses to my paper by Christopher Bache and Nancy Evans Bush. Journal of NearDeath Studies, 13, 55-64.

Sabom, M. (1982). Recollections of death: A medical investigation. New York, NY: Harper and Row.

Zaleski, C. (1987). Otherworld journeys: Accounts of near-death experience in medieval and modern times. New York, NY: Oxford University Press. 